Journal of English Language Teaching and Applied Linguistics

ISSN: 2707-756X

DOI: $10.32996 /$ jeltal

Journal Homepage: www.al-kindipublisher.com/index.php/jeltal

\title{
Teaching Interpreting for Tourism Purposes
}

\author{
Reima Al-Jarf \\ Full Professor of ELT, ESP and Translation, King Saud University, Riyadh, Saudi Arabia \\ Corresponding Author: Reima Al-Jarf, E-mail: reima.al.jarf@gmail.com
}

\section{ARTICLE INFORMATION ABSTRACT}

Received: 08 October 2021

Accepted: 23 November 2021

Published: 31 December 2021

Dol: $10.32996 /$ jeltal.2021.3.13.3

\section{KEYWORDS}

Interpreting for specific purposes, tourism purposes, interpreting instruction, tourism interpreting, student interpreters, interpreter training, interpreting courses
This article proposes a model for teaching interpreting for tourism purposes. It shows the aims of the model, interpreting materials, training strategies, training environment and assessment techniques. The model aims to train students to interpret in English with or without prior preparation or knowledge of the topic and without taking or reading form notes. The training model consists of the following exercises: (i) breathing exercises; (ii) memory training exercises; (iii) shadowing exercises; (iv) sentence paraphrasing; (v) summarizing sentences, then whole paragraphs about tourism; (vi) listening to single words, sentences, and a short paragraph about tourism and interpreting them; (vii) listening to familiar and easy tourism topics, then more difficult ones with a variety of tourism sub-topics. In a multimedia language lab, the students may listen to tourism podcasts, watch tourism documentaries or TED Talks and interpret the content from English to Arabic and vice versa. Simulations (role playing) of tourists and interpreters in teams of three or more may be conducted. Students may also visit a local tourist attraction, interpret, or give a commentary on-site. The training program objectives, types of interpreting, interpreting exercises, training materials, teaching and learning strategies and assessment techniques are described in detail.

\section{Introduction}

Current developments in the tourism industry (air travel, hotel, catering, entertainment, sightseeing and shopping services) have made it easy for foreign tourists to travel to foreign countries. Some tourists travel for holiday and recreational purposes, others travel for business, religious, health, educational, cultural, industrial purposes, and others. Increasing overseas tourism highlights the importance of language services for travel and tourism to better communicate with visitors. Foreign tourists usually need interpreters to help them communicate and learn about the foreign country they are visiting, and help them understand the local culture, environment, natural landscapes, and tourist attractions. Tourism and travel interpreters can affect tourists' experience to a great extent. They can help tourists feel welcome in the foreign environment and provide familiarity and understanding of the tourist destinations. Having an interpreter shows hospitality, fosters trust, and increases overall satisfaction. Tourism and travel interpreters provide international tourists with education and a deeper understanding of and personal connection to the foreign places they are visiting. They stimulate, facilitate, and extend tourists' understanding of the place or attractions they are visiting and develop empathy towards the heritage, conservation, culture, and landscape in the country being visited (Scamman², 2018; Makopo, Geldenhuys \& Sime, 2018; Weng, Liangac, \& Bao, 2020). In addition, Makopo, Geldenhuys and Sime (2018) indicated that tourist guides' interpretation helps in understanding visitor satisfaction, and gathering information related to whether the attributes of a tourist attraction match visitors' preferences. This information will help tourist attraction marketers improve the quality of their products and services to meet visitors' preferences.

Due to the importance of tourism and travel interpreting, numerous studies in the literature focused on developing students translation competence since it is the ultimate goal of interpreter training. The most important component of translation competence is bilingual sub-competence because language proficiency and communicative competence are indicative of the rate of employment of interpreting graduates. Language proficiency is very important in the tourism and hospitality industry due

Copyright: (C) 2021 the Author(s). This article is an open access article distributed under the terms and conditions of the Creative Commons Attribution (CC-BY) 4.0 license (https://creativecommons.org/licenses/by/4.0/). Published by Al-Kindi Centre for Research and Development, London, United Kingdom.

\footnotetext{
${ }^{2}$ https://telelanguage.com/blog/tourism-and-travel-interpreters-helping-businesses-connect-with-international-guests/
} 
to its specific nature and because English is the most widely used language in international tourism. Hence it is necessary to teach English for tourism purposes with a special focus on developing the speaking skills of students planning to become interpreters in the field of tourism (Carrasco Flores, 2021; Pacurar \& Mihele, 2020; Zahedpisheh, Abu Bakar \& Saffari, 2017; AlJarf, 2021b; Al-Jarf, 2021d; Al-Jarf, 2007a).

Another aspect of translation competence is developing students' pragmatic competence in interpreting, understanding, and using language correctly and appropriately in a particular context to be able to communicate successfully and effectively (Lu, 2019). Lu classified pragmatic failure in interpreting into three categories: pragma-linguistic failure (when words and expressions are transferred from language A to language B without taking their pragmatic meaning into consideration); socio-pragmatic failure (when a translator misuses or misunderstands the social conditions associated with the language in use); and malaproppragmatic failure (interpreter's slips of the tongue or the wrong use of one word in place of another).

In addition to being a language expert knowing the local idioms and dialects, an interpreter should be fully fluent in the source language (SL) and target language (TL). Al-Jarf (2018) found that limited vocabulary knowledge and the inability to discriminate and identify spoken phonemes in unfamiliar words caused difficulties in auditory comprehension of spoken texts and interpreting problems. Al-Jarf (2018) also indicated that background or world knowledge has a significant effect on auditory comprehension in interpreting courses. Interviews with students showed that the major source of difficulty in interpreting courses was unfamiliarity with foreign proper names such as names of presidents, prime ministers, foreign countries, states, cities, organizations, and acronyms. Therefore, a student interpreter should have sufficient vocabulary knowledge in the tourism field, world knowledge and auditory identification, discrimination, and comprehension ability to be able to understand different English accents of tourists visiting the country.

An interpreter in tourism should be a culture expert with in-depth experience in the SL and TL cultures. He/she should be able to interpret cultural differences to avoid any cultural confusion. He/she should be a location(s) expert as well, who knows in detail the area to be travelled, who is able to recommend various places to eat, who can give background information on locations along the way. He/she should be friendly, personable, and trustworthy and should be professional throughout the interactions with visitors ${ }^{3}$.

A second line of research in the literature identified the good characteristics of interpreting. For instance, Chiu and Huang (2020) reported five effective interpreting principles in culinary heritage tourism from the perspective of suppliers and consumers. Those principles include: (i) personalizing with heritage owners; (ii) assuring hands-on experience; (iii) facilitating post-event sharing; (iv) reaching the environment, and ( $v$ ) showcasing all possible traditions. Owners and operators can design interpreting services that connect heritage owners, facilitate private sharing moments, create pre-event warm-up, inspire visitors to revitalize and showcase holistic content.

Similarly, Benton (2009) investigated four interpretating goals or conceptions in cultural interpreting programs: (i) connecting visitors to resources; (ii) encouraging environmental literacy; (iii) conveying agency mission and influencing behavior; and (iv) promoting tourism outcomes. The study found that connecting visitors to resources was presented in all the programs, but the other three conceptions were not present in them.

In China, Weng, Liangac and Bao (2020) revealed that interpersonal interpretation of the World Heritage sites of Wulingyuan, in Hunan province, outperformed non-personal interpretation in delivering heritage values. The tourists focused more on the contents of the interpretation rather than the media used for delivering the interpretation. The researchers concluded that tour guides should interpret the cultural values of heritage sites. Awareness of the interpreting strategy to be used and interpreting norms allow interpreters to be efficient and resourceful in achieving the communication goals. The researchers concluded that there is a need for incorporating strategy training, especially when interpreters are trained to interpret into the TL.

A third line of research investigated the techniques and strategies that tourism interpreters use. In Indonesia, Saputra, Saragih, Lubis and Muchtar (2017) pointed out that tour guides use eight techniques in consecutive and liaison interpreting of the meanings of heritage sites in North Sumatra. Those techniques were: simplification; summarizing; explanation; anticipation; deletion of information; reformulating the wording of the original text to maintain the right distance from the speaker; dividing up the speaker's sentences into a number of short, self-contained chunks and then linking them in an appropriate way; and generalization, i.e., expressing a number of specific items mentioned in one generic term. Summarizing was the most dominant interpreting technique that tour guides in North Sumatra use.

\footnotetext{
${ }^{3}$ https://www.languagescientific.com/what-is-escort-interpreting/
} 
In a study conducted with Chinese student interpreters, Dong, Li and Zhao (2019) revealed that the strategies that student interpreters employed more frequently were those recommended by their instructors, such as explicitation. The less frequently used strategies were those which their instructors advised them to use with caution, such as approximation. The strategies that the students did not use were those that their instructors did not recommend, such as guessing. The frequency of using explicitation strategies positively correlated with students' interpreting performance. The guessing strategy negatively correlated with students' interpreting performance. The results suggested that strategy acquisition is plausible and strategy training is effective.

In Taiwan, Wu and Liao (2018) developed a trainee-friendly strategy model and a taxonomy to help the students understand how strategies fit into a larger picture. They re-categorized interpreting strategies into: problem-solving, problem-preventing, and message-enhancing. They also streamlined, renamed, adjusted, and grouped the strategies under four catchy principles: Be Clear, Be Concise, Be Flexible, and One Chunk at a Time. This instructional framework activated cognitive, metacognitive, and social-affective aspects of learning to interpret.

In Japan, Yamada, Skibins and Weiler (2021) tested the feasibility of Western-based interpretation competencies in training nonWestern interpreting guides. They found that interpreter training programs in Japan were successful in improving student interpreters' perceptions of the importance of connecting individual roles and organisational goals; thematic, organised, relevant, enjoyable (TORE) qualities; story development; and reflection. Training programs also improved student interpreters' perceptions of their capacity with relation to thematic, relevant, organised, and enjoyable qualities. However, the programs did not affect students' ratings of their capacity to use storytelling or to foster reflection in their interpreting tours. They concluded that Western interpreting competencies could successfully enable Japanese interpreting guides to follow best practice to meet interpreting and organisational goals. The researchers recommended practice and reflective opportunities in interpreter training.

In China, Zhang and Yu (2018) examined the interplay between memory training and interpreting quality with reference to Chinese and English language pairs. By focusing on different memory training methods among beginning and advanced interpreting students, the researchers found that memory training exerted a significant favourable effect on student interpreters' performance. Memory allocation training played a more important role than memory capacity training in student interpreters' development. Memory capacity training was more beneficial for student interpreters who were beginners, while memory allocation training proved to be more helpful for interpreting students who were gaining more experience in learning to interpret. It was concluded that an effective combination of memory capacity and memory allocation training is necessary in teaching interpreting in order to achieve an overall effect on student interpreters' performance.

Although numerous universities in Saudi Arabia have translation programs, there is a need for establishing a training program for tourism and travel interpreters for numerous reasons. Saudi Arabia has been popular for business visitors, and pilgrims visiting the two Holy cities of Makkah and Madinah all year round for a long time. The Saudi government has recently started to encourage foreign tourists from all countries to visit the kingdom for holiday and recreational purposes. They have been organizing tourism campaigns, different types of tours especially to historical places such as Mada'in Saleh and Al-Ola that are part of the World Cultural Heritage, music festivals, Riyadh Season Activities, beaches, resorts in Aseer region and others. They have made visa procedures easier than before. The influx of tourist need accommodation, food, sight-seeing services and above all interpreting services. Current interpreting services are insufficient as translation and interpreting programs available at some Colleges of Languages and Translation in Saudi Arabia train students in general interpreting, but no special programs for training tourism and travel interpreters are being offered by those colleges. Therefore, this study aims to propose a model for teaching interpreting for tourism, hospitality, and travel purposes to students at Colleges of Languages and Translation in Saudi Arabia. It will show the aims of the model, interpreting materials, teaching and learning strategies, training environment, training schedule and training assessment.

\section{Target Students}

The model proposed in the current study is designed for students who have finished their listening, speaking, reading, writing, grammar and vocabulary building courses in languages and translation departments at Saudi universities and are about to start their interpreting courses, i.e., those who have never had any interpreting training before.

\section{Types of Interpreting}

Interpreting is the oral translation of what someone is saying in another language, to allow two speakers who do not know each other's language to communicate and understand each other. There are different types of interpreting depending on the mode, setting and whether the interpreting is conducted in-person, over-the-phone, or via video remote. Each type is described below. 
According to setting, interpreting can be classified into:

1) Escort or travel or visitor interpretation: This is used when tourists visit attractions and interpreters tell a story about the attraction's significance and its physical, aesthetic, social, natural, or spiritual values. Its purpose is informal education and first-hand participatory learning about the heritage site or natural environment (Cave \& Jolliffe, 2012). An escort or travel interpreter translates orally everything that tourists/visitors and hosts says from language $A$ to language $B$ and vice versa and understands everything that is being said ${ }^{4}$. The interpreter acts as a cultural liaison. $\mathrm{He} / \mathrm{she}$ is in charge of everything from ordering food to settling business deals. Escort interpreting is used in meet-andgreet, interviews, sightseeing tours, event hosting and visits to a site or city. An escort interpreter may interpret for a single visitor, a small or a large group of visitors. Escort interpreting can be in the form of simultaneous, liaison or consecutive interpreting depending on the situation.

2) Conference interpreting: It is used at conferences, lectures, training sessions, meetings, presentations, international business gatherings, large seminars, workshops and similar events. The audience is usually given a set of headphones that are connected to language channels from which they choose a particular language. Interpreters sit in a closed booth, which gives them privacy and helps reduce distractions and noise. Conference interpreting is usually a direct audio feed from the interpreter to the audience. The interpreter translates simultaneously what the speaker is saying, with about 2-second delay. Depending on the length of the session, two interpreters are sometimes recruited so that they take turns in interpreting and take a break to be able to give accurate interpreting 5 .

3) Court interpreting: It refers to all kinds of legal interpreting in a courtroom, police departments, legal offices, prisons, immigration authorities and so on. Court interpreters usually interpret all kinds of legal cases and deal with people of different age groups, social status, educational levels, and cultural backgrounds. Its purpose is to enable the client to participate in the proceedings and help the claimants, who usually belong to an immigrant community, and the adjudicating body understands each other and exchange messages effectively. Court interpreters may use simultaneous or consecutive interpreting depending on the situation and what the court prefers ${ }^{6}$.

4) Business interpreting: It is used in international business meetings attended by businessmen speaking different languages to facilitate communication among them. Business interpreters may use simultaneous, consecutive or liaison interpreting if more than two languages are being used. They help businessmen understand what is being discussed in the meeting to ensure that they are comprehending the true meaning of the speeches being delivered in their own language ${ }^{7}$. Business interpreters may help clients in sightseeing while they are travelling for business. They may accompany them to a single meeting, or a number of meetings.

5) Medical interpreting: It is used between doctors, nurses and patients who speak different languages. Hospitals and clinics sometimes have on-site interpreters, over-the-phone, or video remotes to ensure that patients can easily access their service and communicate effectively. Interpreters who are trained, specialized and skilled in medical interpreting provide a valuable service to patients especially in medical emergencies ${ }^{8}$.

As for mode, interpreting can be classified into:

1) Simultaneous Interpreting: In simultaneous interpreting, the interpreter interprets while the speaker is talking as in conference interpreting, providing a continuous translation that parallels the speaker's speech.

2) Consecutive Interpretation in which the speaker speaks at intervals pausing during his/her speech to give the interpreter time to interpret what has been said up to that point.

3) Liaison interpreting is used during visits of delegations or at small business meetings, a multilingual event, company visits, or commercial negotiations. The interpreter accompanies a group of visitors speaking different languages and interprets between 3 people or small groups speaking different languages to help them communicate with and fully understand each other. The interpret translates from language $A$ to $B$, then listens to the speaker who speaks language $B$ and translates from language $B$ to $A$, then back again to the speaker who speaks language $A$ and interprets from language $A$ to $B$. The interpreter does not usually take notes, but memorizes short segments spoken in one language and reproduces them in the other language. The liaison interpreter should have a good command of both English and Arabic languages and should speak both fluently. He/she should have good concentration skills, a good memory, specialty knowledge in the topic the speakers are talking about, soft skills, should be empathetic, should understand and accepting different cultures.

\footnotetext{
${ }^{4}$ https://www.languagescientific.com/what-is-escort-interpreting/

${ }^{5}$ Conference Interpreting | Interpreter Services (ititranslates.com)

${ }^{6}$ https://www.translatum.gr/journal/5/court-interpreting.htm

${ }^{7}$ https://www.daytranslations.com/blog/effective-business-interpreting/

${ }^{8}$ www.daytranslations.com/blog/industries-interpreting-services/
} 
4) Sight interpreting: It refers to interpreting a written text without prior preparation. The source text is turned into an oral-or signed-target text in the TL in real time ${ }^{9}$.Sight interpreters usually work in a courtroom, or at a notary or lawyer's office when the client must understand the contents of a document written in a foreign language. Sight interpreting requires excellent language skills, a quick thinking, the ability to avoid stress, and the ability to maintain good attention and concentration. What is challenging for the interpreter is a lack of familiarity with the content of the documents and their context and being expected to read and interpret the required fragments in no time at all. To give a correct, coherent, and fluent interpretation of a document, the sight interpreter, must take in as much as possible of the written text in the document and interpret it into the TL immediately ${ }^{10}$.

5) Whispered (in-person) interpreting: It is a type of simultaneous interpreting that does not involve any equipment. It is suitable for events or meetings where there is only one guest in the entire room who does not understand the language of the speaker. Here the interpreter sits slightly behind the guest and interprets the original speech directly to the guest's ear ${ }^{11}$.

\section{Teaching Interpreting for Tourism Purposes}

Interpreting in the tourism and travel field is a branch of language interpreting. It usually refers to teaching interpreting to university students who are planning to work in the tourism industry or people who are already employed in the tourism and travel sectors, who need to acquire specialized tourism vocabulary and interpreting skills needed for the job. As with any interpreting course, a tourism interpreting course may focus on one or more travel and tourism subfields such as hotel management, travel agency operation and management, marketing, event management, convention industry, airline operation, heritage interpretation, cultural, adventure, beach, conference, business, culinary, religious (pilgrimage), educational, ethnic, health (medical, wellness), fashion, film, historical (heritage), industrial, cruise, jungle, marine, mountain, nature, safari, water, wildlife, recreational, rural, shopping, sports, urban, virtual tourism, and ecotourism.

Interpreting in the tourism field is different from general interpreting in that the interpreting instructor needs to be proficient in English and must also be knowledgeable in the different tourism sub-fields. Some interpreting scholars recommend a two-layer interpreting course in tourism: the first layer covers all generic knowledge in interpreting skills, and the second layer focuses on the specifics of the specialization of the individual, i.e., specialized vocabulary and structures in business, medical, religious, airline, culinary, historical entertainment tourism sub-fields and so on (Al-Jarf, 2006).

\section{The Tourism Interpreter Training Model}

The interpreter training model proposed in the present study aims to develop students' proficiency level in both English (L2) and Arabic (L1); ability to interpret from English to Arabic and from Arabic to English, i.e., switching languages easily; concentrate on the meaning, not on the words; retain the main ideas instead of the original words without taking notes; convey the sense without repeating each phrase; convey the message in the correct language; use the good expression, speak/interpret in front of an audience with a normal speed; maintain eye contact with the audience and create a warm atmosphere (Al-Jarf 20151; Al-Jarf, 2015b; Al-Jarf, 2007b).

\subsection{Training Materials}

According to Al-Jarf (2000), the training material in tourism, hospitality and travel interpreting can be collected from tourism magazines, brochures, YouTube documentaries, tourism podcasts, TED talks on tourism, and tourism glossaries (Al-Jarf, 2021e; Al-Jarf, 2012). The students can suggest tourism documentary videos, podcasts, magazines, brochures, and articles that are of interest to them and may practice interpreting from English to Arabic and vice versa. The training materials consist of tourism vocabulary items, tourism sentences and expressions, and tourism texts from different tourism subfields. Examples of the materials for tourism interpreter training are:

- Tourism terms such as tour, accommodation, resort, guide, escort, event management, hospitality, cuisine, gallery, museum, collection, artifacts, archaeology, statue, paintings, festival, costumes, square, sight-seeing, coach, cultural heritage, fine dining, ecotourism, tourist attraction, and others.

- Sentences that cover different aspects of Saudi history and culture, folklore, food, sports, celebrations and holidays, current events, economic, educational and health system, historical places, heritage sites, local regions, and others. Sentences and phrases about tourist attractions can also be collected from English and Arabic linguistic landscapes in the local environment (Al-Jarf, 2021d).

\footnotetext{
${ }^{9}$ www.researchgate.net/publication/348018414_Sight_interpretingtranslation

${ }^{10}$ mLingua / Services / Interpretation / Sight interpreting

${ }^{11} \mathrm{https}$ //translationandinterpreting.com/types-of-interpreting/\#Whispering_Chuchotage
} 
- Written and spoken tourism texts that cover different aspects of Saudi history and culture, folklore, food, sports, celebrations and holidays, current events, economic, educational and health system, historical places, UNESCO World Heritage sites, local regions, cultural festivals such as Jamahiriya Festival, amusement parks, recreation parks, ancient mosques, music festivals, museums, galleries, traditional costumes, and jewellery, local food, traditional sports such as camel races.

The training material should represent different subject areas in tourism, hospitality and travel, and should increase in length, topic familiarity, and difficulty level.

\subsection{Training Stages}

Interpreting training goes through the following stages:

1) Breathing exercises: At the beginning of each class session, the students practice taking a deep breath, i.e., inhaling while counting from 1-12, and then they breathe out, i.e., exhale while counting from 1-12 for few minutes only. Breathing exercises help boost concentration, help the students focus and stay centered.

2) Speech shadowing exercises: These involve listening to a speaker on TV, on a radio show, or podcast, and pausing the audio at natural breaks to repeat exactly what the speaker has said. They listen to a model such as a video or audio of someone speaking first in Arabic and then in English, and they repeat what the speaker is saying in real-time. The students may listen to a commentator/narrator in a documentary and repeat what they hear after the commentator/narrator. They repeat the exact words they hear in the same intonation, speed and pauses. They listen to commentator/narrator in English, and they repeat what they have heard after the commentator/narrator in English, i.e., the students listen and repeat in the same language. They do not interpret at this stage. They do not pause. They repeat word for word, phrase by phrase, what they have exactly heard, with as little delay as possible. The narrator should be a couple of words ahead of the student. This exercise is practiced at the beginning of the course, for 10 minutes or so for few sessions only. The students may practice speech shadowing independently to improve their pronunciation and intonation.

3) Sentence paraphrasing: Here the students listen to English tourism sentences selected from tourism sources and reproduce their meaning in their own words in the same language (English-English). Then they listen to Arabic sentences selected from any tourism source and reproduce their meaning in their own words in the same language (Arabic-Arabic). No transfer of meaning from one language to the other is done. Paraphrasing exercises enhance students' ability to make syntactic and semantic changes, to process the SL at the structural and informational levels. The articulation and checking of the paraphrased version of a sentence also help enhance students' comprehension and organization of the SL, leading to better interpreting into the TL (Cheung, 2016).

4) Summarizing sentences. First, the students provide summaries of sentences, then longer paragraphs selected from tourism resources. They summarize the texts in the same language as the ST whether it is English or Arabic. No translation is done. Everything is done fast. Once the students listen, they have to start summarizing what they have heard without delay and without writing anything on paper. This activity promotes interpreting efficiency. Research showed that student interpreters' summarizing performance significantly correlated with their interpreting performance and predicted their efficiency in their overall interpreting performance, completeness, and information accuracy (Li, 2018).

5) Memory training exercises in which the instructor starts by giving students tourism words, then easy short tourism texts to interpret. The students are trained to use mnemonic devices ${ }^{12}$ to help them remember the spoken text such as:

(i) Visualization, i.e., forming an image while listening to a speech the students in order to remember as in visualizing food, a historical place or a natural view.

(ii) Segmentation, i.e., remembering sentences in chunks, as smaller bits of information are easier to remember. This is similar to breaking phone numbers down into groups. When listening to a long dialogue, the students group the different topics they hear to help them remember them more easily.

(iii) Memory bating, i.e., associating multiple points or details with few key ones that the students have already memorized and breaking an entire dialogue up according to keywords.

(iv) Doodling flowers, shapes, circles, boxes, or sketches of objects on a notepad while listening to a speaker to help the students concentrate. The students can even incorporate some of the visualization techniques and draw symbols that will help them remember what is being said.

6) Interpreting easy tourism texts with familiar topics. The students listen to easy recorded interviews, documentary or texts with familiar tourism, hospitality and travel topics in English and interpret them into Arabic, then they listen to

12 http://interpretertrain.com/5-essential-memory-training-exercises-for-medical-interpreters/ 
recorded interviews documentaries or texts with familiar tourism, hospitality and travel topics in Arabic and interpret them into English. The students interpret the same number of English and Arabic interviews, documentaries, and/or texts. They should not take notes while listening, nor translate anything on paper and read it. They start interpreting easy tourism texts with familiar topics. The texts increased in length, difficulty level and topic familiarity. Texts should be selected from different tourism, hospitality and travel subfields as mentioned above. They practice making predictions while listening using their prior knowledge (Al-Jarf, 2012).

In each session, the students interpret several types of tourism texts. To expand the students' lexical knowledge, the instructor gives a set of basic terminology related to the tourism texts to be interpreted. To develop the students' world knowledge, they may read or watch extra tourism material on specific topics on their own out of class (Al-Jarf, 2015a; Al-Jarf, 2015b; Al-Jarf, 2007b).

\subsection{Training Schedule}

The breathing, speech shadowing, sentence paraphrasing, short text summarizing, and memory training exercises are practiced in the first 2 weeks of the course. In each training session, student interpreters practice several memory-training activities for 1015 minutes each. Each week, they practice interpreting several tourism dialogs, interviews, documentaries, and texts in one session. Either half the session is devoted to interpreting from English to Arabic, the other half to interpreting from Arabic to English, or one whole session is devoted to English-Arabic interpretation and the following session to Arabic-English interpretation. They listen to each dialog, documentary or text in segments or as a whole only once depending on whether they are practicing liaison, consecutive or simultaneous interpreting. Focus should be on interpreting the overall meaning, not the exact words of what they hear because it is impossible to store every single word they hear in their memory. When they hear a word that is difficult for them, they can give an explanatory equivalent from context rather than leaving it out from the translation.

\subsection{Teaching and Learning Strategies}

Students learn and practice how to begin and conclude an interview or commentary. They learn to greet the audience, introduce themselves before getting into the interpreting task and thank the audience, say goodbye, give instructions or follow up directions for the next day, next stage or next event. They practice liaison, consecutive or simultaneous interpreting depending on the situation. They listen for sense right from the start of training program and focus less on the exact words of what they hear. They practice storing units of meaning from the spoken text rather than discrete words in the text. They learn to make predictions while listening. They infer the topic of the dialogue or spoken text from the first sentence, keep the topic in mind while listening, ignore redundancies and repetitions, pay attention to what is being said about the main topic. To help students cope with spoken texts with difficult topics, they are trained to simplify the text that they heard, i.e., paraphrase it silently in the same SL before rendering the meaning in the TL. They do not have to render lists of points in the TL in the same order in the SL. They practice visualizing (form a mental picture) events and places, and use their prior knowledge (knowledge of the world) to connect the ideas that they have heard in source text with what they already know. They learn to cope with grammatical and lexical difficulties in the source text by giving the gist of what they have heard and paraphrasing the words they are having difficulty with. To expand the students' lexical knowledge, the instructor can give a set of basic tourism terminology in the different tourism sub-fields. The students learn to note the context in which a word is used such as interest and give the equivalent accordingly. They learn to interpret the underlying meaning of the word, not the surface meaning as in the word element. The instructor demonstrates how a text should be interpreted. She listens to each student while interpreting, notes errors and slips. Extralinguistic aspects of interpreting are practiced. When interpreting for tourists, note-taking is kept to a minimum and is allowed in some cases such as business meetings with few people who do not speak the same language.

\subsection{Training Environment}

Interpreting training can be conducting in the following modes:

(1) Multimedia language lab: With headphones on, the students listen to a tourism audio, podcast, video clip or a text read by the instructor in short intervals, and they interpret them (Al-Jarf, 2021c).

(2) Simulation/Role Playing: The Students practice simulated interpreting (e.g., tour commentary) in teams of 3-5. Before the session, the teacher assigns a tourism topic. The students research the topic and present it in English and Arabic. Other students interpret the Arabic version to English and the English version to Arabic.

(3) On-site practice: The students may visit a tourist attraction, a restaurant, a hotel, a travel agency, a cultural site or historical place in the local environment with their instructor and speak about the place they are visiting for few minutes. They can read about the place they are going to visit in English or Arabic a head of time and then talk about it in English or Arabic for few minutes on-site. 
(4) Home Practice: At home the students can watch YouTube videos and observe how professional interpreters and tour guides' work. They can also watch documentary videos or podcasts in the SL and TL (English and Arabic) for the same topics and note the English expressions and the Arabic equivalents used. They can practice interpreting while watching a T.V. or YouTube documentary, a TED Talk and while listening to an audio (podcasts) about a tourism topic. The students can practice individually, in pairs or in small teams (Al-Jarf, 2021d).

\subsection{Assessment}

The students take two Interm tests and a final exam at the end of the semester. The exams should be oral and should consist of several dialogs and/or spoken texts covering a variety of tourism topics. The test material should not have been seen or practiced before. The tourism test material should be of the same difficulty level as the material practiced. For interpreting assessment, two modes of assessment can be used. The first is lab assessment and the second is face-to-face or on-site assessment. In the lab assessment procedure, the students listen to a dialog, spoken text, podcast, documentary or TED Talk in short intervals or as a whole, depending on the type of interpreting mode assessed. Each segment is heard only once. The students may jot down names and figures (statistics). They record their interpretation using an MP4 player right after they hear the source text. The students may not write down the translation and then read it (Al-Jarf, 2021a).

In the face-to-face assessment procedure, the students are tested in small groups. They engage in simulated tourism situations. They may also listen to recordings, podcasts or watch videoclips about tourism topics, then interpret orally in front of the instructor. The instructor prepares a set of tourism situation, recordings, and video clips for the students to interpret. Each group randomly draws one or more interpreting tasks from a basket. They read the task and engage in interpreting the spoken text, interview, conversation, commentary with other members of the group. A student may play the role of a tour guide and other students as tourists. She gives a commentary on a selected tourism topic. The students take turns to speak as a business, or escort interpreter. The instructor may also ask the students to comment on a picture showing a tourist attraction in the SL or TL. The students may engage in on-site interpreting, where they speak about a tourist attraction in the local community. Each team completes the conversation and/or commentary in 10-15 minutes or less.

To grade students' interpretation in both assessment procedures, the instructor uses an assessment rubric that consists of 4 skills: (i) content and comprehension, (ii) fluency, intonation and voice control, (iii) pronunciation, and (iv) grammatical correctness; and 5 performance levels: Excellent, Very Good, Good, Below Average, \& Poor. 50\% of the test mark is allocated to the quality and accuracy of the interpretation rendered by the student, and $50 \%$ for fluency, intonation, voice control, pronunciation, and grammatical correctness (See Table 1). The instructor prints a scoring rubric for each interpreting task on paper and allocates one scoring sheet to each student. For each interpreting task, the instructor ticks the level of performance for each skill that reflects a student's performance and records a score in each cell as in Table 1. Scoring rubrics can be shown to the students after grading and comments can be written on each student's scoring sheet (Al-Jarf, 2021a).

In the lab assessment procedure, the instructor listens to the recorded interpretations while following a printed version of the dialog or spoken text. She uses holistic evaluation and the scoring rubric describe above. Focus should be on the student's ability to understand and render the sense of what she has heard. The instructor records interpreting errors and gives comments to each student on her scoring sheet.

In the face-to-face assessment procedure, the instructor grades the students' interpretation right away once a team is finished with their tasks. Comments are written on each team's scoring sheet.

Table 1: Scoring Rubric for Interpreting Tests with Marks Allocated to Each Performance Level

\begin{tabular}{|c|c|c|c|c|c|}
\hline \multirow[b]{2}{*}{ Skills } & \multicolumn{5}{|c|}{ Performance Levels } \\
\hline & Excellent & $\begin{array}{l}\text { Very } \\
\text { Good } \\
\end{array}$ & Good & $\begin{array}{c}\text { Below } \\
\text { Average }\end{array}$ & Poor \\
\hline 2. Fluency, intonation, voice control & 5 & 4 & 3 & 2 & 1 \\
\hline 3. Pronunciation & 5 & 5 & 3 & 2 & 1 \\
\hline
\end{tabular}




\section{Conclusion}

The current article proposes a model for teaching interpreting for tourism purposes to an undergraduate student majoring in translation in Saudi Arabia. The author has applied this model in teaching interpreting to undergraduate students majoring in translation at the College of Language and Translation, Kins Saud University, in Riyadh, Saudi Arabia, over several semesters. Comparisons of pre and posttests scores of experimental students who practiced interpreting using the model and control students who did not, showed significant differences in interpreting skill development. Students who practiced interpreting as delineated in the current model could interpret fluently in both directions (English-Arabic and Arabic-English) without hesitation and without taking notes. They could convey the meaning of the source text, not the meanings of discrete words in the text. They could store units in their memory, paraphrase lexical items which were unfamiliar. The students reported that they found the interpreting practice procedures in the model were fun and beneficial. They indicated that they benefited from the gradation of the teaching material and exercises, the quantity and variety of spoken texts selected from different tourism fields. On the contrary, students in the control group lacked fluency, the instructor would dictate the text to them, they write it on paper, translate it on paper and read the translation out loud to the instructor or MP4 player. They found the interpreting task a chore and could not remember the overall meaning of the spoken text. They had auditory identification, discrimination, and comprehension and interpreting difficulties (Al-Jarf, 2018; Al-Jarf, 2015a; Al-Jarf, 2015b, Al-Jarf, 2000).

Finally, effective interpreting instruction using the proposed model proposed depends on the instructor's teaching competence. Therefore, interpreting instructors should receive some orientation about the interpreting training model through training workshops. They should be introduced to the different types of tourism topics and subfields. Interpreting instructors for tourism purposes should teach tourism terminology and grammatical structures in context. Listening, and speaking activities can be based on tourism topics. Focus should be on understanding and translating the overall meaning of a tourism text, not on the literal meaning of every single word in the oral text. The instructor should encourage the students to be active. The students should have an active role in the interpreting classroom. They may identify the difficult words and structures, speak, translate, bring tourism texts, articles, podcasts, videos, TES Talks of interest to them. The learning environment should be secure for making mistakes. Focus should be on communication and conveying the meaning in the $T L$, not on correcting every single error made by the students. Students should receive feedback on their interpreting performance and areas of improvement. At the end of the course, students and instructors' feedback is significant for the continual improvement of interpreter training. To take full advantage of the proposed interpreting training model and to continue to make adjustments to it, the study recommends that future researchers try out the model with samples of students enrolled in different levels of interpreting courses, compare the students pre and posttest scores and survey students and instructors' views of the training.

Funding: This research received no external funding. The APC was funded by Reima Al-Jarf.

Conflicts of Interest: The author declares no conflict of interest.

\section{References}

[1] Al-Jarf, Reima (2021a). EFL female college students and instructors' preferred method of speaking assessment: A perspective from Saudi Arabia. Asian Journal of Education and Social Studies (AJESS), 16(3), 38-50. doi: 10.9734/ajess/2021/v16i330403

[2] Al-Jarf, R. (2021b). EFI speaking practice in distance learning during the coronavirus pandemic 2020-2021. International Journal of Research - GRANTHAALAYAH, 9(7), 179-196. doi: 10.29121/granthaalayah.v9.i7.2021.4094

[3] Al-Jarf, R. (2021c). Feasibility of digital multimedia language labs for interpreting instruction as perceived by interpreting instructors in Saudi Arabia. International Journal of Linguistics, Literature and Translation (IJLLT), 4 (4), 70-79. ERIC Number ED613819. Doi: 10.32996/ijlt.2021.4.4.8.

[4] Al-Jarf, R. (2021d). Teaching English with linguistic landscapes to Saudi students studying abroad. Asian Journal of Language, literature, and Culture Studies (AJL2CS), 4(3), 1-12. www.journalajl2c.com/index.php/AJL2C/article/view/30148/56568.

[5] Al-Jarf, R. (2021e). TED talks as a listening resource in EFL College classrooms. International Journal of Language and Literary Studies (ijlls), 2(3), 256-267. https://doi.org/10.36892/ijlls.v2i3.691. ERIC Number: ED615127.

[6] Al-Jarf, R. (2018). Effect of background knowledge on auditory comprehension in interpreting courses. In R. Jancarikova (Ed.) Interpretation of Meaning across Discourse, 97-108. Muni Press, Brno, Czech Republic. https://munispace.muni.cz/library/catalog/view/999/3104/763-1/\#preview

[7] Al-Jarf, R. (2015a). Consecutive interpreting teaching guide. Retrieved from https://www.researchgate.net/publication/284177869

[8] Al-Jarf, R. (2015b). Liaison interpreting teaching guide. Retrieved from www.researchgate.net/publication/280947154

[9] Al-Jarf, R. (2012). Online videos for specific purposes. Journal of Education and Social Research (JESR), 2(6), 17-21. Italy. https://doi.org/10.5901/ichss-2012-vol-07.

[10] Al-Jarf, R. (2007a). From reticence to fluency: the effect of TBLT on students' speaking ability. International Conference on Task-Based Language Teaching (TBLT), September 21-23, 2005. Centre for Language and Migration, University of Leuven, Belgium. https://www.researchgate.net/publication/284177675

[11] Al-Jarf, R. (2007b). How to teach liaison interpreting to beginners. Foundations for a Pedagogy of Arabic Translation Conference. University College Francisco Ferrer Brussels, Belgium. October 18-20. ERIC Number: ED613512. 
[12] Al-Jarf, R. (2006). Teaching translation for specific purposes. 3rd conference of the Association of Professors of English and Translation at Arab Universities (APETAU). Amman, Jordan. August 23-25. https://www.researchgate.net/publication/348815104

[13] Al-Jarf, R. (2000). Bridging the gap between teacher and learner in liaison interpreting. TESOL Arabia' 2000 Conference, "Bridging the Gap between Teacher and Learner". Al-Ain, UAE, April 12-14.

[14] Benton, G. M. (2009). From principle to practice: four conceptions of interpretation. Journal of Interpretation Research, 14(1), 7-3. Doi: $10.1177 / 109258720901400102$.

[15] Bowen, D. \& Bowen, M. (1990). Interpreting: Yesterday, today, and tomorrow. John Benjamins Publishing.

[16] Carrasco Flores, J. A. (2021). Analysing "English for translation and interpreting" materials: skills, sub-competences and types of knowledge. Interpreter and Translator Trainer, 15(3), 326-342.

[17] Cave, J. and Jolliffe, L. (2012). Visitor interpretation: the key concepts. In P. Robinson (Ed.) Tourism: The Key Concepts. London: Routledge. 273-275.

[18] Cheung, A. (2016). Paraphrasing exercises and training for Chinese to English consecutive interpreting. FORUM Revue internationale d'interprétation et de traduction. International Journal of Interpretation and Translation 14(1),1-18. DOI: 10.1075/forum.14.1.01che.

[19] Chiu, S. T. C. \& Huang, W. J. (2020). Effective Principles of culinary heritage tourism interpretation. ScholarWorks@UMass Amherst. https://core.ac.uk/display/334980321

[20] Dong, Y., Li, Y. \& Zhao, N. (2019). Acquisition of interpreting strategies by student interpreters. Interpreter and Translator Trainer, 13(4), 408-425.

[21] Li, Y. (2018). How does student interpreters' interpreting performance relate to their performance in summarizing? International Journal of Linguistics and Communication, 6(2), 53-58. DOI: 10.15640/ijlc.v6n2a6

[22] Lu, L. (2019). Pragmatic failure in interpretation and the development of students' pragmatic competence in interpreting. English Language Teaching, 12(3), 37-45.

[23] Makopo, B., Geldenhuys, S. \& Sime, L. (2018). The role of tourist guides in interpretation: a survey of secondary school teachers at Maropeng and the Sterkfontein caves, South Africa. African Journal of Hospitality, Tourism and Leisure, 7 (1).

[24] Pacurar, E. \& Mihele, R. (2020). Language instruction in tourism education: beyond the vocational field. Romanian Review of Geographical Education, 9(2), 5-22.

[25] Saputra, B., Saragih, A., Lubis, S. \& Muchtar, M. (2017). Study of the interpreting techniques used by the tourist guides in the tourism attractions of North Sumatra. International Journal of English Language \& Translation Studies, 5(3), 14-20. http://www.eltsjournal.org/archive/value5\%20issue3/3-5-3-17.pdf

[26] Weng, L.; Liang, Z. \& Bao, J. (2020). The effect of tour interpretation on perceived heritage values: A comparison of tourists with and without tour guiding interpretation at a heritage destination. Journal of Destination Marketing \& Management, 16, June. https://doi.org/ 10.1016/j.jdmm.2020.100431

[27] $\mathrm{Wu}, \mathrm{Y}$. \& Liao, P. (2018). Re-conceptualising interpreting strategies for teaching interpretation into a B language. Interpreter and Translator Trainer, 12(2), 188-206.

[28] Yamada, N., Skibins, J. \& Weiler, B. (2021) "Applying interpretation principles to a nonwestern (Japanese) training context. International Journal of Tour Guiding Research, 2(1), 3-16.

[29] Zahedpisheh, N., Abu Bakar, Z. B. \& Saffari, N. (2017). English for tourism and hospitality purposes (ETP). English Language Teaching, 10(9), 86-94.

[30] Zhang, W. \&Yu, D. (2018). Can memory training help improve interpreting quality? a case report in China. Interpreter and Translator Trainer, 12(2), 152-165. 